\title{
Correction to: The Dynamics of Ascaris lumbricoides Infections
}

\author{
A. C. Fowler ${ }^{1,2} \cdot$ T. Déirdre Hollingsworth ${ }^{3,4}$ \\ Published online: 29 August 2018 \\ (c) Society for Mathematical Biology 2018
}

\section{Correction to: Bull Math Biol (2016) 78:815-833 https://doi.org/10.1007/s11538-016-0164-2}

In the original article, the second author's name was incorrect in the metadata. The given name is T. Déirdre, and the family name is Hollingsworth.

The correct citation for this article is as follows:

Fowler, A.C. \& Hollingsworth, T. Déirdre, Bull Math Biol (2016) 78: 815. https:// doi.org/10.1007/s11538-016-0164-2

The original article can be found online at https://doi.org/10.1007/s11538-016-0164-2.

$凶 \quad$ A. C. Fowler andrew.fowler@ul.ie

1 MACSI, University of Limerick, Limerick, Ireland

2 OCIAM, University of Oxford, Oxford, UK

3 Mathematics Institute, University of Warwick, Coventry, UK

4 Liverpool School of Tropical Medicine, Liverpool, UK 